NASA Contractor Report 202339

ICOMP-97-05

\title{
Effect of Coannular Flow on Linearized Euler Equation Predictions of Jet Noise
}

R. Hixon and S.-H. Shih

Institute for Computational Mechanics in Propulsion

Cleveland, Ohio

Reda R. Mankbadi

Cairo University

Cairo, Egypt

May 1997

Prepared for

Lewis Research Center

Under Cooperative Agreement NCC3-531

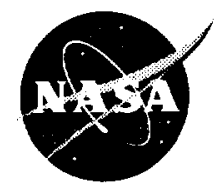

National Aeronautics and

Space Administration 
. 


\title{
Effect of Coannular Flow on Linearized Euler Equation Predictions of Jet Noise
}

\author{
R. Hixon* and S.-H. Shih ${ }^{\dagger}$ \\ Institute for Computational Mechanics in Propulsion \\ NASA Lewis Research Center \\ Cleveland, $\mathrm{OH} 44135$ \\ R. R. Mankbadi $§$ \\ Mechanical Power Engineering Dept. \\ Cairo University \\ Cairo, Egypt
}

\begin{abstract}
An improved version of a previously validated linearized Euler equation solver is used to compute the noise generated by coannular supersonic jets. Results for a single supersonic jet are compared to the results from both a normal velocity profile and an inverted velocity profile supersonic jet.
\end{abstract}

\section{Introduction}

The full, compressible Navier-Stokes equations govern the process of sound generation and propagation to the far field. To solve these equations without resorting to modeling the turbulent quantities, Direct Numerical Simulation (DNS) may be employed. However, the resolution required to accurately simulate high-Reynolds-number turbulent flows make DNS calculations impractical due to current computer limitations.

Therefore, Mankbadi et. al. ${ }^{1,2}$ proposed the extension of the Large Eddy Simulation (LES) approach for use in the prediction of sound generation and propagation. In this approach,

This paper is declared a work of the U.S. Government and is not subject to copyright protection in the United States.

* Senior Research Associate, Member AIAA.

† Senior Research Associate, Senior Member AIAA.

$\S$ Senior Scientist and Leader, Computational Aeroacoustics; Associate Fellow AIAA. 
the Navier-Stokes equations are filtered into large-scale components, which are calculated directly, and small-scale components, which are modeled. In a LES calculation, the noise generated by the small-scale components is not captured; however, it is known that the large-scale structures are more efficient than the small ones at radiating noise (e.g., Refs. 37). The LES approach has been used successfully to predict the noise radiated by a supersonic jet, but it is still a CPU-intensive approach, especially for three-dimensional calculations of far-field noise. However, this limitation may be bypassed by using either a Linearized Euler Equation (LEE) solver ${ }^{8}$ or a Kirchhoff method ${ }^{9-12}$ to calculate the far-field noise radiation.

The present work is concerned with exploring the use of the less computationally demanding LEE solver for supersonic jet noise predictions. The LEE approach neglects both viscosity and nonlinear effects. The viscous effects can be neglected since the largescale dynamics in free shear flows are essentially inviscid (e.g., Ref. 13). Nonlinearity, however, seems to be important (e.g., Ref. 14).

Yet, much of the physics can be obtained by considering the linear equations. Several attempts have succeeded in studying the physics of jet noise based on a simplified form of the Euler equations (e.g., Ref. 15-18). The linearized Euler equations simultaneously describes the near field, where the sound is generated, and the propagation of sound to the far field. As such, the problem of matching the near field hydrodynamic disturbances to the far field acoustic propagation does not arise. The linearized Euler equations fully account for non-parallel flow effects and for the simultaneous presence of non-discrete frequencies.

In the past, the linearized Euler equations have been used to compute the instability noise generated by supersonic jets ${ }^{19,20}$. Parametric studies have been performed to investigate the effects of jet temperature ${ }^{21}$, and the effect of random inflow disturbances has been 
shown ${ }^{22}$. Other researchers have added nonlinear terms to the linearized Euler equations, but their magnitude and effect are uncertain ${ }^{23}$.

\section{Governing Equations}

Starting from the full Navier-Stokes equations in conservative form, neglecting viscosity, linearizing about a given mean flow

$$
\left(\begin{array}{c}
\bar{\rho} \\
U \\
V \\
W \\
E
\end{array}\right)=\left(\begin{array}{c}
\bar{\rho} \\
V_{r} \\
V_{\theta} \\
V_{z} \\
E
\end{array}\right)
$$

and separating the azimuthal modes, the linearized Euler equations may be written in cylindrical coordinates as:

$$
(r \tilde{Q})_{t}+(r \tilde{F})_{z}+(r \tilde{G})_{r}=\tilde{S}-i n \tilde{H}
$$

where $\mathrm{n}$ is the azimuthal mode and:

$$
\begin{gathered}
\tilde{Q}=\left\{\begin{array}{c}
\rho^{\prime} \\
u^{\prime} \\
v^{\prime} \\
w^{\prime} \\
e^{\prime}
\end{array}\right\}=\left\{\begin{array}{c}
\rho_{n}^{\prime} \\
\left(\rho v_{r}\right)_{n}^{\prime} \\
\left(\rho v_{\theta}\right)_{n}^{\prime} \\
\left(\rho v_{z}\right)_{n}^{\prime} \\
e_{n}^{\prime}
\end{array}\right\} \\
\tilde{F}=\left\{\begin{array}{c}
w^{\prime} \\
-\rho^{\prime} U W+u^{\prime} W+w^{\prime} U \\
-\rho^{\prime} V W+v^{\prime} W+w^{\prime} V \\
\rho^{\prime}+2 w^{\prime} W-\rho^{\prime} W^{2} \\
W\left(p^{\prime}+e^{\prime}\right)+\left(w^{\prime}-\rho^{\prime} W\right)\left(\frac{P+E}{\bar{\rho}}\right)
\end{array}\right\}
\end{gathered}
$$




$$
\begin{gathered}
\tilde{G}=\left\{\begin{array}{c}
u^{\prime} \\
p^{\prime}+2 w^{\prime} W-\rho^{\prime} W^{2} \\
-\rho^{\prime} U V+v^{\prime} U+u^{\prime} V \\
-\rho^{\prime} U W+u^{\prime} W+w^{\prime} U \\
U\left(p^{\prime}+e^{\prime}\right)+\left(u^{\prime}-\rho^{\prime} U\right)\left(\frac{P+E}{\bar{\rho}}\right)
\end{array}\right\} \\
\tilde{S}=\left\{\begin{array}{c}
\rho^{\prime}+2 v^{\prime} V-\rho^{\prime} V^{2} \\
-\rho^{\prime} U V+v^{\prime} U+u^{\prime} V \\
0 \\
0
\end{array}\right\}
\end{gathered}
$$

and

$$
\bar{H}=\left\{\begin{array}{c}
v^{\prime} \\
-\rho^{\prime} U V+v^{\prime} U+u^{\prime} V \\
\rho^{\prime}+2 v^{\prime} V-\rho^{\prime} V^{2} \\
-\rho^{\prime} V W+v^{\prime} W+w^{\prime} V \\
V\left(p^{\prime}+e^{\prime}\right)+\left(v^{\prime}-\rho^{\prime} V\right)\left(\frac{P+E}{\bar{\rho}}\right)
\end{array}\right\}
$$

Here

$$
\begin{aligned}
& p^{\prime}=(\gamma-1)\left[\begin{array}{c}
e^{\prime}-\left(u^{\prime} U+v^{\prime} V+w^{\prime} W\right) \\
+\frac{1}{2} \rho^{\prime}\left(U^{2}+v^{2}+w^{2}\right)
\end{array}\right] \\
& P=(\gamma-1) \bar{\rho}\left[E-\frac{1}{2}\left(U^{2}+V^{2}+w^{2}\right)\right]
\end{aligned}
$$

Velocities are normalized by the reference jet exit centerline velocity $U_{c}$, time by $D / U_{c}$, density by the jet exit centerline value $\rho_{e}$, and pressure by $\rho_{c} U_{c}{ }^{2}$. Here, $D$ is the reference jet nozzle diameter. 


\begin{tabular}{|c|c|c|c|}
\hline & Reference & $\begin{array}{c}\text { Normal Velocity } \\
\text { Profile }\end{array}$ & $\begin{array}{c}\text { Inverted Velocity } \\
\text { Profile }\end{array}$ \\
\hline $\mathrm{U}_{\text {inner }}(\mathrm{m} / \mathrm{s})$ & 1330.0 & 1534.6 & 823.7 \\
\hline $\mathrm{U}_{\text {outer }}(\mathrm{m} / \mathrm{s})$ & -.....-. & 1227.7 & 1441.4 \\
\hline $\mathrm{T}_{\text {inner }}\left({ }^{\circ} \mathrm{K}\right)$ & 1100.0 & 1692.3 & 1678.4 \\
\hline $\mathrm{T}_{\text {outer }}\left({ }^{\circ} \mathrm{K}\right)$ & - & 846.2 & 808.1 \\
\hline $\mathrm{M}_{\text {inner }}$ & 2.0 & 1.9 & 1.0 \\
\hline$M_{\text {outer }}$ & -......... & 2.1 & 2.5 \\
\hline
\end{tabular}

Table 1: Supersonic coannular jet test cases

In Eq. (2), a periodic distribution is assumed for the azimuthal direction; for example,

$$
\left\{\begin{array}{c}
\rho^{\prime} \\
v_{r}^{\prime} \\
v_{\theta^{\prime}} \\
v_{z^{\prime}} \\
p^{\prime}
\end{array}\right\}_{n}=\left\{\begin{array}{c}
\rho^{\prime} \\
v_{r}^{\prime} \\
v_{\theta}^{\prime} \\
v_{z^{\prime}} \\
\rho^{\prime}
\end{array}\right\} e^{i n \theta}
$$

In this formulation, each additional mode calculated adds another set of equations to be solved. The advantages to this formulation are: lowered storage and computation, improved centerline behavior, and improved boundary condition specification. 


\begin{tabular}{|c|c|c|c|}
\hline & $\begin{array}{c}\text { Reference } \\
\text { (inner }->\infty \text { ) }\end{array}$ & $\begin{array}{c}\text { Normal Velocity } \\
\text { Profile } \\
\text { (inner }->\infty)\end{array}$ & $\begin{array}{c}\text { Inverted Velocity } \\
\text { Profile } \\
(\text { outer }->\infty)\end{array}$ \\
\hline $\mathrm{M}_{\mathrm{C}} \mathrm{K}_{\mathrm{K}-\mathrm{H}}$ & $\begin{array}{c}1.97 \\
\left(\theta=59.6^{\circ}\right)\end{array}$ & $\begin{array}{c}2.03 \\
\left(\theta=60.5^{\circ}\right)\end{array}$ & $\begin{array}{c}2.19 \\
\left(\theta=62.8^{\circ}\right)\end{array}$ \\
\hline$\left.\mathrm{M}_{\mathrm{C}}\right|_{\text {supersonic }}$ & $\begin{array}{c}1.32 \\
\left(\theta=40.6^{\circ}\right)\end{array}$ & $\begin{array}{c}1.33 \\
\left(\theta=41.3^{\circ}\right)\end{array}$ & $\begin{array}{c}1.56 \\
\left(\theta=50.3^{\circ}\right)\end{array}$ \\
\hline $\mathrm{M}_{\mathrm{C}_{\text {subsonic }}}$ & 0.659 & 0.631 & 0.939 \\
\hline
\end{tabular}

Table 2: Predicted Instabilities and Approximate Emission Angles

\section{Mean Flow}

The mean flows used in these test cases were computed using a Parabolic Navier-Stokes (PNS) numerical solver provided by Dr. Milo Dahl, which is documented in Ref. 24. There were three test cases computed, shown in Table 1.

In these test cases, the thrust and mass flow of the three jets are held constant. The coannular jets have an area ratio $A_{2} / A_{1}$ of 1.25 , and a radius ratio $r_{2} / r_{1}$ of 1.5 . The Normal Velocity Profile test case corresponds to Dahl's case 5, and the Inverted Velocity Profile test case corresponds to Dahl's case 24.

In heated supersonic jets, there are three possible types of instability waves: the classical Kelvin-Helmholtz instability waves, supersonic instability waves, and subsonic instability waves. The convective Mach numbers for the three families of instabilities are given in 
Seiner, et. al.'s ${ }^{25}$ work as:

$$
\begin{aligned}
\left.M_{C}\right|_{K-H} & =\frac{\left(v_{j e t}+c_{j e t}\right)}{\left(c_{j e t}+c_{\infty}\right)} \\
\left.M_{C}\right|_{\text {supersonic }} & =\frac{V_{j e t}}{\left(c_{j e t}+c_{\infty}\right)} \\
\left.M_{C}\right|_{\text {subsonic }} & =\frac{\left(V_{j e t}-c_{j}\right)}{\left(c_{j e t}+c_{\infty}\right)}
\end{aligned}
$$

When the convective Mach number is greater than unity, that instability may be sustained by the jet. An estimate of the Mach wave emission angle is given by:

$$
\theta=\cos ^{-1}\left(\frac{1}{M_{C}}\right)
$$

Table 2 gives a listing of the convective Mach numbers for these three families of waves as well as the estimated Mach wave emission angle. Notice that the shear layer between the inner and outer cores of the coannular jets may also support instabilities.

Velocity profiles for these three cases are given in Figure 1, and the velocity magnitude along the radial center of each jet are given in Figure 2.

\section{Numerical Algorithm}

The code uses a new MacCormack-type solver, which is formally fourth order accurate in time and space. This extension of the MacCormack scheme uses Tam and Webb's Dispersion Relation Preserving methodology in its derivation. This scheme is described in greater detail in Ref. 26 , and has been validated against the $2-4$ scheme, which is another MacCormack-type solver. The 2-4 scheme was described by Gottlieb and Turkel ${ }^{27}$ and Bayliss and Maestrello 28 . 
The 2-4 scheme has been used successfully on a wide range of fluid and aeroacoustics problems ${ }^{29-32}$. Sankar, Reddy, and Hariharan ${ }^{33}$ have evaluated this scheme for aeroacoustics applications. The solution procedure for the new scheme is as follows:

In the present code, the optimized 4-6 Runge-Kutta time marching scheme of $\mathrm{Hu}$, et. al. ${ }^{34}$, is employed:

$$
\tilde{Q}^{k+4}=L_{4}^{F B F B} L_{6}^{B F B F B F} L_{4}^{B F B F} L_{6}^{F B F B F B} \tilde{Q}^{k}
$$

where $\mathrm{k}$ denotes the time level, $\mathrm{L}_{4}$ and $\mathrm{L}_{6}$ denote four- and six-stage Runge-Kutta time integrations, and the superscripts $\mathrm{B}$ and $\mathrm{F}$ denote backward and forward spatial differencing.

Note that the number of stages in the time marching procedure alternates between four and six. This procedure can be written as:

$$
\begin{aligned}
& \tilde{Q}^{(1)}=\tilde{Q}^{k} \\
& \tilde{Q}^{(2)}=\bar{Q}^{k}+\left(\begin{array}{c}
1 / 2 \\
0.353323
\end{array}\right) \Delta t F\left(\tilde{Q}^{(1)}\right) \\
& \tilde{Q}^{(3)}=\tilde{Q}^{k}+\left(\begin{array}{c}
1 / 2 \\
0.999597
\end{array}\right) \Delta t F\left(\tilde{Q}^{(2)}\right) \\
& \tilde{Q}^{(4)}=\tilde{Q}^{k}+\left(\begin{array}{c}
1 \\
0.152188
\end{array}\right) \Delta t F\left(\tilde{Q}^{(3)}\right) \\
& \tilde{Q}^{(5)}=\tilde{Q}^{k}+\left(\begin{array}{c}
0 \\
0.534216
\end{array}\right) \Delta t F\left(\tilde{Q}^{(4)}\right) \\
& \tilde{Q}^{(6)}=\tilde{Q}^{k}+\left(\begin{array}{c}
0 \\
0.603907
\end{array}\right) \Delta t F\left(\tilde{Q}^{(5)}\right)
\end{aligned}
$$




$$
\tilde{Q}^{k+1}=\tilde{Q}^{k}+\Delta t\left[\begin{array}{c}
\left(\begin{array}{c}
1 / 6 \\
0.0467621
\end{array}\right) F\left(\tilde{Q}^{(1)}\right)+\left(\begin{array}{c}
1 / 3 \\
0.137286
\end{array}\right) F\left(\tilde{Q}^{(2)}\right)+ \\
\left(\begin{array}{c}
1 / 3 \\
0.170975
\end{array}\right) F\left(\tilde{Q}^{(3)}\right)+\left(\begin{array}{c}
1 / 6 \\
0.197572
\end{array}\right) F\left(\tilde{Q}^{(4)}\right)+ \\
\left(\begin{array}{c}
0 \\
0.282263
\end{array}\right) F\left(\tilde{Q}^{(5)}\right)+\left(\begin{array}{c}
0 \\
0.165142
\end{array}\right) F\left(\tilde{Q}^{(6)}\right)
\end{array}\right](14
$$

where the values of the upper coefficients are used in the four stage step and those of the lower coefficients are used in the six-stage step. Each derivative uses biased differencing, either forward or backward, providing inherent dissipation for the solver. Unlike the earlier MacCormack-type schemes, the stencil is not fully one-sided.

Using a radial derivative at point $j$ as an example,

Forward:

$$
\left.\frac{\partial \tilde{Q}}{\partial r}\right|_{i}=\frac{-1}{\Delta r}\left(\begin{array}{l}
0.30874 \tilde{Q}_{i-1}+0.6326 \tilde{Q}_{i}-1.2330 \tilde{Q}_{i+1} \\
+0.3334 \tilde{Q}_{i+2}-0.04168 \tilde{Q}_{i+3}
\end{array}\right)^{k}
$$

Backward:

$$
\left.\frac{\partial \tilde{Q}}{\partial r}\right|_{i}=\frac{1}{\Delta r}\left(\begin{array}{l}
0.30874 \tilde{Q}_{i+1}+0.6326 \tilde{Q}_{i}-1.2330 \tilde{Q}_{i-1} \\
+0.3334 \tilde{Q}_{i-2}-0.04168 \tilde{Q}_{i-3}
\end{array}\right)^{k}
$$

The sweep directions are reversed between each stage of the time marching scheme to avoid biasing, and the first sweep direction in each time step is alternated as well.. At the computational boundaries, flux quantities outside the boundaries are needed to compute the spatial derivatives, and these are extrapolated using third-order extrapolation based on data from the interior of the domain. 
Due to the extremely sharp gradients of the shear layer near the inflow boundary, additional dissipation was required to damp out high-frequency errors in the jet shear layer. To accomplish this, sixth-order dissipation was added in the shear layer as:

$$
F(\tilde{Q})=F(\tilde{Q})+0.03\left(\begin{array}{l}
\tilde{Q}_{i-3}-6 \tilde{Q}_{i-2}+15 \tilde{Q}_{i-1}-20 \tilde{Q}_{i} \\
+15 \tilde{Q}_{i+1}-6 \tilde{Q}_{i+2}+\tilde{Q}_{i+3}+\tilde{Q}_{j-3} \\
-6 \tilde{Q}_{j-2}+15 \tilde{Q}_{j-1}-20 \tilde{Q}_{j}+15 \tilde{Q}_{j+1} \\
-6 \tilde{Q}_{j+2}+\tilde{Q}_{j+3}
\end{array}\right)
$$

\section{Computational Grid}

The grid used for these cases was 341 (radial) x 461 (axial) points. In the radial direction, the minimum spacing was $\Delta r / D=0.01$ at the centerline, smoothly stretching to 0.13 at $r / D$ $=16$. In the axial direction, the minimum spacing was $\Delta \mathrm{z} / \mathrm{D}=0.04$ at the $\mathrm{z}=0$ boundary, smoothly stretching to 0.13 at the $z / D=35$ boundary. The maximum spacing corresponds to 10 points per wavelength, which is well within the accuracy range of this code. All three cases used the same computational grid. A Courant number of 1.25 was used for these computations.

\section{Boundary Conditions}

Special attention is given to the boundary treatment in order to avoid non-physical oscillations which can render the computed unsteady solution unacceptable. Several boundary treatments were considered. 35.36 The boundary treatments discussed below were found to be stable, essentially non-reflecting, and suitable for the present jet noise computations. 


\section{Inflow Boundary Conditions}

At the inflow boundary $(z / D=0)$, the radial boundary is split into hydrodynamic disturbance and radiation regimes, which are treated differently as outlined below.

\section{Inflow Disturbance}

At the hydrodynamic inflow boundary $(\mathrm{r} / \mathrm{D}<2)$, a small random disturbance is introduced. In space, the disturbance has the form of a 3rd order polynomial in order to obtain smooth derivatives in all directions, with a semi-random time component:

$$
\begin{aligned}
& \left\{\begin{array}{c}
\rho^{\prime} \\
v_{r^{\prime}} \\
v_{\theta^{\prime}} \\
v_{z^{\prime}} \\
\rho^{\prime}
\end{array}\right\}_{n}=\left[\varepsilon \sum_{f=1}^{N F R E Q}\left\{\begin{array}{c}
e^{i\left(\omega+\phi_{1 f}\right) t} \\
e^{i\left(\omega+\phi_{2 f}\right) t} \\
0 \\
e^{i\left(\omega+\phi_{4 f}\right) t} \\
e^{i\left(\omega+\phi_{5 f}\right) t}
\end{array}\right\}\right]_{n} A(r, z) \\
& A(r, z)=1+2 R^{3}-3 R^{2}
\end{aligned}
$$

where

$$
\begin{aligned}
& R=\sqrt{(r-1)^{2}+z^{2}} \\
& \varepsilon=10^{-4}
\end{aligned}
$$

A random number generator is used to determine the phase of each component of each mode and frequency. In this preliminary work, a Strouhal number of 0.2 was used. This Strouhal number was set using the conditions at the exit plane of the reference jet for compatibility.

To introduce the input disturbance into the flow field, the time derivatives of the disturbance are added to the computed flow variables at each time step:

$$
\left(\tilde{Q}_{t}\right)_{\text {boundary }}=\left(\tilde{Q}_{t}\right)_{\text {computed }}+\left(\tilde{Q}_{t}\right)_{\text {disturbance }}
$$




\section{Hydrodynamic Disturbance Regime}

In the hydrodynamic disturbance regime $(r / D<2)$, the Thompson inflow boundary condition is used ${ }^{37.38}$. In the Thompson analysis, the axial operator is decomposed into five 1-D characteristics. At a subsonic inflow boundary, four of these characteristics are incoming, and are set to zero for a non-reflecting boundary condition, while the fifth characteristic is outgoing and is computed from the flow solution:

$$
\begin{aligned}
& R_{1}=p_{t}{ }^{\prime}+\bar{\rho} \bar{c}\left(v_{z^{\prime}}\right)_{t}=0 \\
& R_{2}=p_{t}^{\prime}+\bar{c}^{2} \rho_{t}^{\prime}=0 \\
& R_{3}=\bar{\rho} \bar{c}\left(v_{r^{\prime}}\right)_{t}=0 \\
& R_{4}=\bar{\rho} \bar{c}\left(v_{\theta}^{\prime}\right)_{t}=0 \\
& R_{5}=p_{t}^{\prime}-\bar{\rho} \bar{c}\left(v_{z^{\prime}}\right)_{t}=\left(p_{t}^{\prime}-\bar{\rho} \bar{c}\left(v_{z^{\prime}}\right)_{t}\right)_{\text {computed }}
\end{aligned}
$$

The five characteristic equations are then solved together to obtain the time derivatives of the variables at the inflow boundary. For a supersonic inflow, all characteristics are incoming, and all are set to zero. In order to prevent spurious oscillations, the amplitude of the outgoing characteristic was smoothly reduced to zero near the sonic line.

Due to the specified disturbance at the hydrodynamic inflow boundary, the Thompson inflow boundary condition exhibited a problem in which some disturbances were convected in a radial direction and remained on the boundary for the rest of the computation. To alleviate this, the mean radial velocity was set to zero on the inflow boundary, and smoothly raised to the proper value by $z / D=0.7$.

\section{Radiation Regime}

In the radiation regime $(r / D>2)$, the conventional acoustic radiation boundary condition 
applies:

$$
q_{t}=-V(\theta)\left[\frac{z}{R} q_{z}+\frac{r}{R} q_{r}+\frac{1}{R} q\right]
$$

where:

$$
\begin{aligned}
& q=\left\{\begin{array}{l}
\rho^{\prime} \\
v_{r^{\prime}} \\
v_{z}^{\prime} \\
p^{\prime}
\end{array}\right\} \\
& R=\sqrt{z^{2}+r^{2}} \\
& V(\theta)=\bar{C}\left[\frac{z}{R} M+\sqrt{1-\left(\frac{r}{R} M\right)^{2}}\right]
\end{aligned}
$$

and $\mathbf{M}$ is the local Mach number. The spatial derivatives which appear in Eq. (22) are evaluated in an identical manner as the inner flow derivatives.

\section{Outflow Boundary Conditions}

The outflow boundary treatment is based on the asymptotic analysis of the linearized equations as given by $\mathrm{Tam}$ and $\mathrm{Webb}^{39}$. The pressure condition is the same as that obtained by Bayliss and Turkel ${ }^{40}$, Enquest and Majda ${ }^{41}$, and Hariharan and Hagstrom ${ }^{42}$, namely:

$$
p^{\prime}{ }_{t}=-V(\theta)\left[\frac{z}{R} \rho_{z}^{\prime}+\frac{r}{R} p_{r}^{\prime}+\frac{1}{R} p^{\prime}\right]
$$

However, for updating the rest of the primitive variables, Tam and Webb have shown that the momentum and continuity equations should be used to account for the presence of entropy and vorticity waves at the outflow boundary. The spatial differencing used in the inner code is employed to evaluate the derivatives which appear in Eq. (25). 
For the outflow boundary at large radius and a local Mach number of less than 0.01 , the outflow condition is replaced by the radiation condition described above.

It must be noted that the Tam and Webb outflow boundary condition is formulated with an assumption that the mean flow is uniform, which is not true for the jet outflow boundary. However, the results given by this boundary condition are quite good, with very little reflection.

\section{Quter Radial Boundary Condition}

At the outer radial boundary $\left(r=r_{\max }, 0<z<z_{\max }\right)$, the radiation boundary condition described above is used.

\section{Centerline Treatment}

In this code, the centerline boundary is represented with a point at the centerline, and a ghost point reflected across the centerline in the radial direction. Without azimuthal mode decomposition, the centerline treatment for a three-dimensional problem is not straightforward, and was addressed by Shih, et. al. ${ }^{43}$ However, using the azimuthal mode decomposition method, the centerline boundary condition becomes straightforward:

$$
\left.r\left\{\begin{array}{l}
F_{1} \\
F_{2} \\
F_{3} \\
F_{4} \\
F_{5}
\end{array}\right\}\right|_{r=0}=0
$$


and

$$
\left.r\left\{\begin{array}{c}
F_{1} \\
F_{2} \\
F_{3} \\
F_{4} \\
F_{5}
\end{array}\right]\right|_{r=-\Delta r}=\left.r\left\{\begin{array}{c}
F_{1} \\
-F_{2} \\
-F_{3} \\
F_{4} \\
F_{5}
\end{array}\right]\right|_{r=\Delta r} e^{i n \pi}
$$

\section{Results}

First, Dahl's PNS solver was run to obtain the mean flows for the three jet test cases. These mean flows were interpolated to fit the LEE grid. The cases tested used a Strouhal number of 0.2 and modes $n=0$ and $n=1$ for each jet. The input disturbance was identical for all three jets. In the interest of brevity, only the results of the $n=1$ mode will be presented.

Figures $3 a-c$ show instantaneous snapshots of the pressure for the $n=1$ mode of all three jets. Notice the preferred direction of radiation, and that there are two families of waves present, radiating at angles very close to the approximate angles given in Table 2. This shows the ability of the linearized Euler equation solver to capture both types of instability without any special treatment.

Figures $4 \mathrm{a}-\mathrm{c}$ show the contours of the radiated sound in $\mathrm{dB}$ for the $\mathrm{n}=1$ mode of all three cases. The magnitudes given are for comparison only, since the true magnitude of sound depends on the unknown amplitude and distribution of the inflow disturbance. Each contour represents a $5 \mathrm{~dB}$ change in the sound pressure level. It can be seen that the NVP jet disturbance reaches its peak farthest upstream, while the IVP jet disturbance continues to grow and peaks much farther downstream.

Figure 5 shows the magnitude of the radiated sound as a function of the angle from the jet centerline. These results are taken at the outer boundary of the computational domain; thus, 
the radius is varying from a minimum of $R=16 \mathrm{D}$ to a maximum of $\mathrm{R}=38.5 \mathrm{D}$. It is shown that the NVP jet is generally quieter than the reference single jet, while the IVP jet is as much as $8 \mathrm{~dB}$ louder.

\section{Conclusions}

This work is designed to illustrate the use of the linearized Euler equations for a parametric study of jet noise, as well as demonstrating the capabilities of the new MacCormack-type solver. The ability of linearized Euler equation solvers to use a mean flow from an existing CFD code in order to compute the noise radiated by instability waves in a supersonic jet is also demonstrated.

\section{Acknowledgements}

The authors would like to acknowledge Dr. Milo Dahl for providing the mean flow solver used in this work. This work was performed under grant NCC3-483 from the NASA Lewis Research Center. Dr. L. A. Povinelli was the Technical Monitor.

\section{References}

1) Mankbadi, R. R., Hayder, M. E., and Povinelli, L. A., 'Structure of Supersonic Jet Flow and Its Radiated Sound', AIAA Journal, Vol. 32, No. 5, May 1994, p. $897-$ 906.

2) Mankbadi, R. R., Shih, S.-H., Hixon, R., and Povinelli, L. A., 'Direct Computation of Acoustic and Flow Field of a Supersonic Jet Using Large-Eddy Simulation', AIAA Paper 95-0680, Reno, NV, Jan. 1995.

3) Seiner, J. M., McLaughlin, D. K., and Liu, C. H., 'Supersonic Jet Noise Generated by Large-Scale Instabilities', NASA TP-2072, Sept. 1982. 
4) Zaman, K. B. M. Q., 'Flow Field and Near and Far Sound Field of a Subsonic Jet', J. Sound and Vib., Vol. 106, 1986, p. 1-6.

5) Mankbadi, R. R. and Liu, J. T. C., 'Sound Generated Aerodynamically Revisited: Large-Scale Structures in a Turbulent Jet as a Source of Sound', Phil. Trans. Royal Soc. London A, Vol. 311, 1984, p. 183-217.

6) Mankbadi, R. R., 'The Self-Noise from Ordered Structures in a Low Mach Number Jet', J. Appl. Mech, Vol. 57, 1990, p. 241-246.

7) Tam, C. K. W. 'Jet Noise Generated by Large-Scale Coherent Motion', Chapter 6 of Aeroacoustics of Flight Vehicles: Theory and Practice. Vol. 1: Noise Source, edited by Hubbard, H. H., NASA RP-1258, 1991.

8) Shih, S.-H., Hixon, R., and Mankbadi, R. R., 'A Zonal Approach for Prediction of Jet Noise', CEAS/AIAA Paper 95-144, Munich, Germany, June 1995.

9) Mankbadi, R. R., Shih, S.-H., Hixon, R., Stewart, J. G., and Povinelli, L. A., 'Extension of Near-Field to Far-Field Jet Noise Predictions', AIAA Paper 962651, July 1996.

10) Lyrintzis, A. S. and Mankbadi, R. R., 'Prediction of the Far-Field Jet Noise Using Kirchhoff's Formulation', AIAA Journal, Vol. 34, No. 2, Feb. 1996, p. 413-416.

11) Meadows, K. R. and Atkins, H. L., 'An Evaluation of a Hybrid Kirchhoff-CFD Approach for Computational Aeroacoustics', Proceedings of the IMACS 14th World Congress, Vol. 2, July 1994, p. 824-827.

12) Pilon, A. and Lyrintzis, A. 'An Improved Kirchhoff Method for Jet Aeroacoustics', AIAA Paper 96-1709, May 1996. 
13) Mankbadi, R. R., 'Dynamics and Control of Coherent Structure in Turbulent Jets', Appl. Mech. Reviews, Vol. 45, No. 6, 1992, p. 219-248.

14) Laufer, J. and Yen, T. C., 'Noise Generation by a Low Mach Number Jet', J. Fluid Mech., Vol. 62, 1983, p. 437-464.

15) Crighton, D. G. and Huerre, P., 'Shear-layer Pressure Fluctuations and Superdirective Acoustic Sources', J. Fluid Mech., Vol. 220, 1990, p. 355-368.

16) Liu, J. T. C., 'Developing Large-Scale Wavelike Eddies and the Near Jet Noise Field', J. Fluid Mech., Vol. 62, 1974, p. 437-464.

17) Tam, C. K. W., 'Supersonic Jet Noise', Annu. Rev. Fluid Mech., Vol. 27, 1995, p. 17-43.

18) Tam, C. K. W. and Burton, D. E., 'Sound Generated by Instability Waves of Supersonic Flows, Part 2: Axisymmetric Jets', J. Fluid Mech., Vol. 138, 1984, p. 273-295.

19) Mankbadi, R. R., Hixon, R., Shih, S.-H., and Povinelli, L. A., 'On the Use of Linearized Euler Equations in the Prediction of Jet Noise', AIAA Paper 95-0505, Reno, NV, Jan. 1995.

20) Hixon, R., Shih, S.-H., and Mankbadi, R. R., 'Direct Prediction of the ThreeDimensional Acoustic Field of a Supersonic Jet Using Linearized Euler Equations', CEAS/AIAA-95-116, June 1995.

21) Hixon, R., Shih, S.-H., and Mankbadi, R. R., 'Numerical Simulation of the Effect of Heating on Jet Noise', FED-Vol. 219, Computational Aeroacoustics, ASME 1995, p. $89-94$. 
22) Hixon, R., Shih, S.-H., and Mankbadi, R. R., 'Effect of Inflow Disturbance on Linearized Euler Equation Prediction of Jet Noise', AIAA Paper 96-0752, Jan. 1996.

23) Bangalore, A., Morris, P. J., and Long, L. N., 'A Parallel Three-Dimensional Compuatational Aeroacoustics Method Using Non-Linear Disturbance Equations', AIAA Paper 96-1728, May 1996.

24) Dahl, Milo D., 'The Aeroacoustics of Supersonic Coaxial Jets', NASA TM 106782, Nov. 1994.

25) Seiner, J. M., Ponton, M. K., Jansen, B. J., and Lagen, N. T., 'The Effects of Temperature on Supersonic Jet Noise Emission', DGLR/AIAA Paper 92-02-046, 1992.

26) Hixon, R. 'On Increasing the Accuracy of MacCormack Schemes for Aeroacoustic Applications', AIAA Paper 97-1586, May 1997.

27) Gottleib, D. and Turkel, E., 'Dissipative Two-Four Method for Time Dependent Problems', Mathematics of Computation, Vol. 30, No. 136, 1976, pp. 703-723.

28) Bayliss, A. and Maestrello, L., 'Simulation of Instabilities and Sound Radiation in a Jet', AIAA Journal, Vol. 19, 1981, p. 835-841.

29) Maestrello, L., Bayliss, A., and Turkel, E., 'On the Interaction of a Sound Pulse with the Shear Layer of an Axisymmetric Jet', J. Sound and Vib., Vol. 74, 1981, p. 281-301.

30) Bayliss, A. and Maestrello, L., 'On the Interaction of a Sound Pulse with the Shear Layer of an Axisymmetric Jet II: Heated Jets', J. Sound and Vib., Vol. 86, 1982, p. $395-409$. 
31) Maestrello, L. and Bayliss, A., 'Flowfield and Far Field Acoustic Amplification Properties of Heated and Unheated Jets', AIAA Journal, Vol. 20, 1982, p. 15391546.

32) Bayliss, A., Maestrello, L., and Turkel, E., 'On the Interaction of a Sound Pulse with the Shear Layer of an Axisymmetric Jet III: Non-Linear Effects', J. Sound and Vib., Vol. 107, 1986, p. 167-175.

33) Sankar, L. N., Reddy, N. N., and Hariharan, N., 'A Comparative Study of Numerical Schemes for Aero-Acoustic Applications', FED-Vol. 147, Computational Aero- and Hydro-Acoustics, AMSE 1993, p. 35-40.

34) Hu, F. Q., Hussaini, M. Y., and Manthey, J., 'Low-Dispersion and -Dissipation Runge-Kutta Schemes for Computational Acoustics', ICASE Report 94-102, Dec. 1994.

35) Hixon, R., Shih, S.-H., and Mankbadi, R. R., 'Evaluation of Boundary Conditions for Computational Aeroacoustics', AIAA Journal, Oct. 1995.

36) Scott, J. N., Mankbadi, R. R., Hayder, M. E., and Hariharan, S. I., 'Outflow Boundary Conditions for the Computational Analysis of Jet Noise', AIAA Paper 93-4366, 1993.

37) Thompson, K. W., 'Time-Dependent Boundary Conditions for Hyperbolic Systems, J. Comp. Physics, Vol. 68, Jan. 1987, p. 1-24.

38) Thompson, K. W., 'Time-Dependent Boundary Conditions for Hyperbolic Systems II', J. Comp. Physics, Vol. 89, 1990, p. 439-461. 
39) Tam, C. K. W., and Webb, J, C., 'Dispersion-Relation-Preserving Finite Difference Schemes for Computational Acoustics', J. Comp. Physics, Vol. 107, 1993, p. 262-281.

40) Bayliss, A. and Turkel, E., 'Far Field Boundary Conditions for Compressible Flows', J. Comp. Physics, Vol. 48, 1982, p. 182-199.

41) Enquest, B. and Majda, A., 'Radiation Boundary Conditions for Acoustic and Elastic Wave Calculations', Communications on Pure and Applied Mathematics, Vol. 32, No. 3, 1979, p. 313-357.

42) Hagstrom, T. and Hariharan, S. I., 'Far Field Expansion for Anisotropic Wave Equations', Computational Acoustics, Vol. 2, 1990.

43) Shih, S.-H., Hixon, R., and Mankbadi, R. R., 'Three-Dimensional Structure in a Supersonic Jet: Behavior Near Centerline', AIAA Paper 95-0681, Reno, NV, Jan. 1995. 

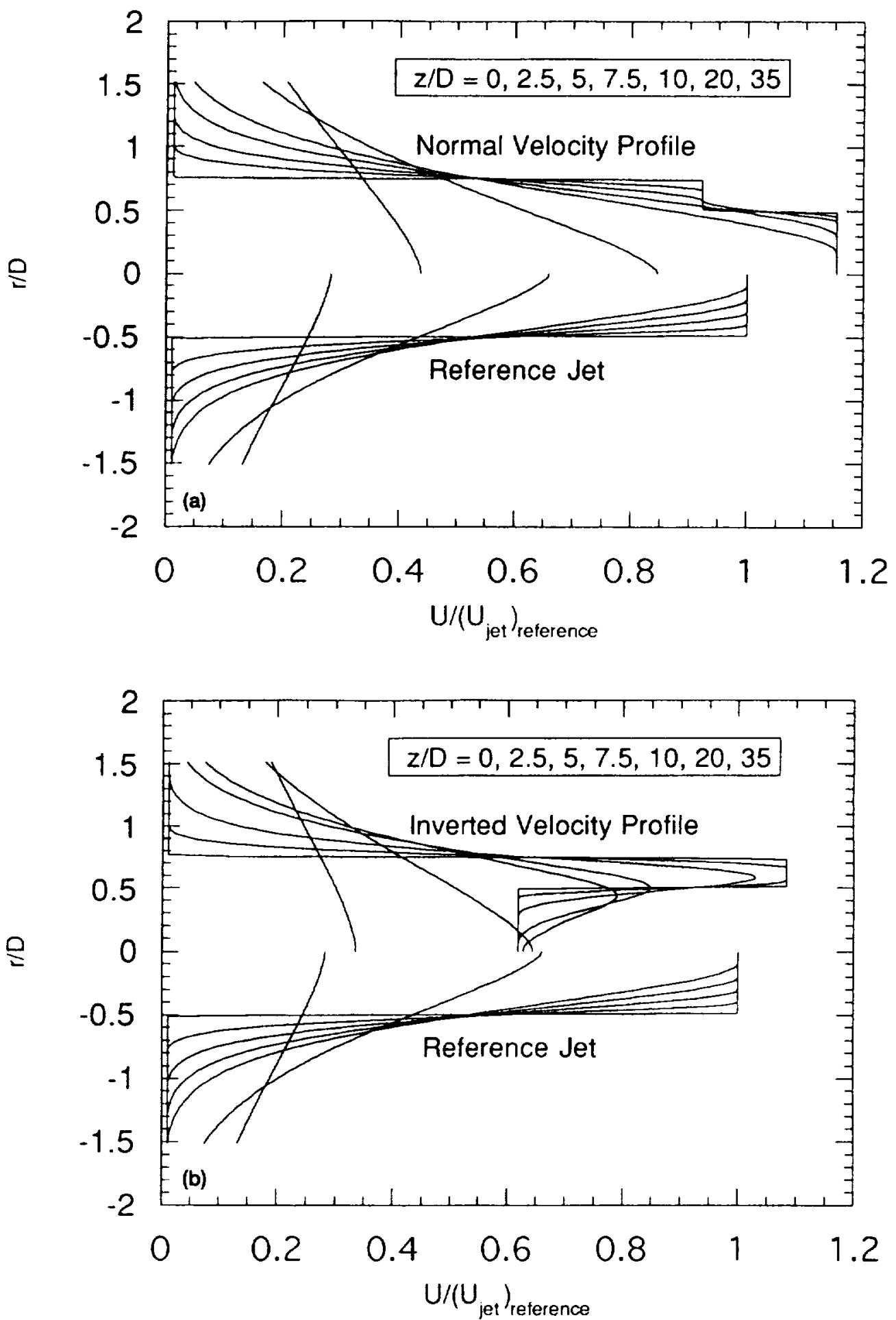

Figure 1.-Mean flow velocity profiles. (a) For normal velocity profile coannular jet. (b) For inverted velocity profile coannular jet. 


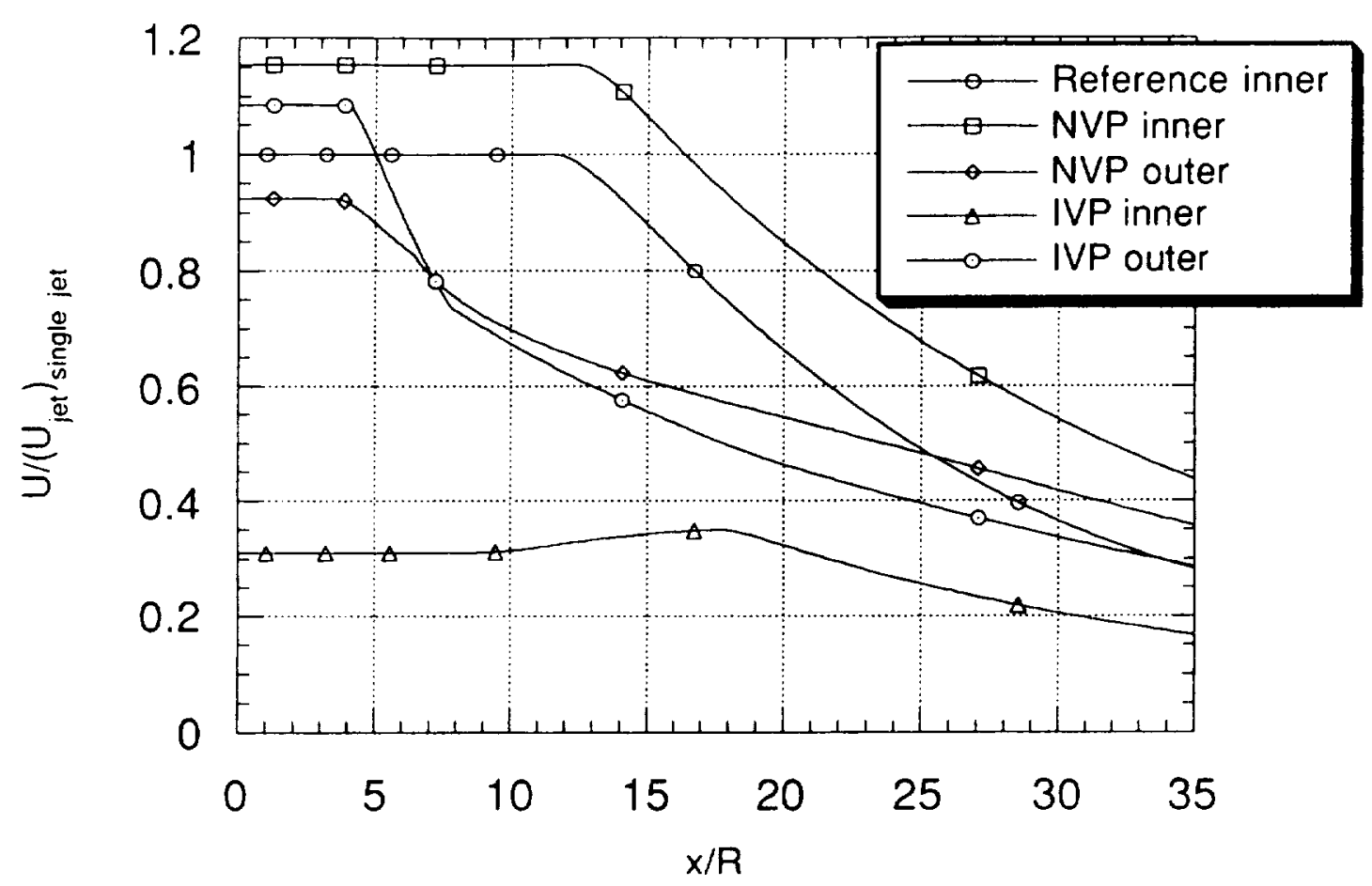

Figure 2.-Core velocities of coannular jets.

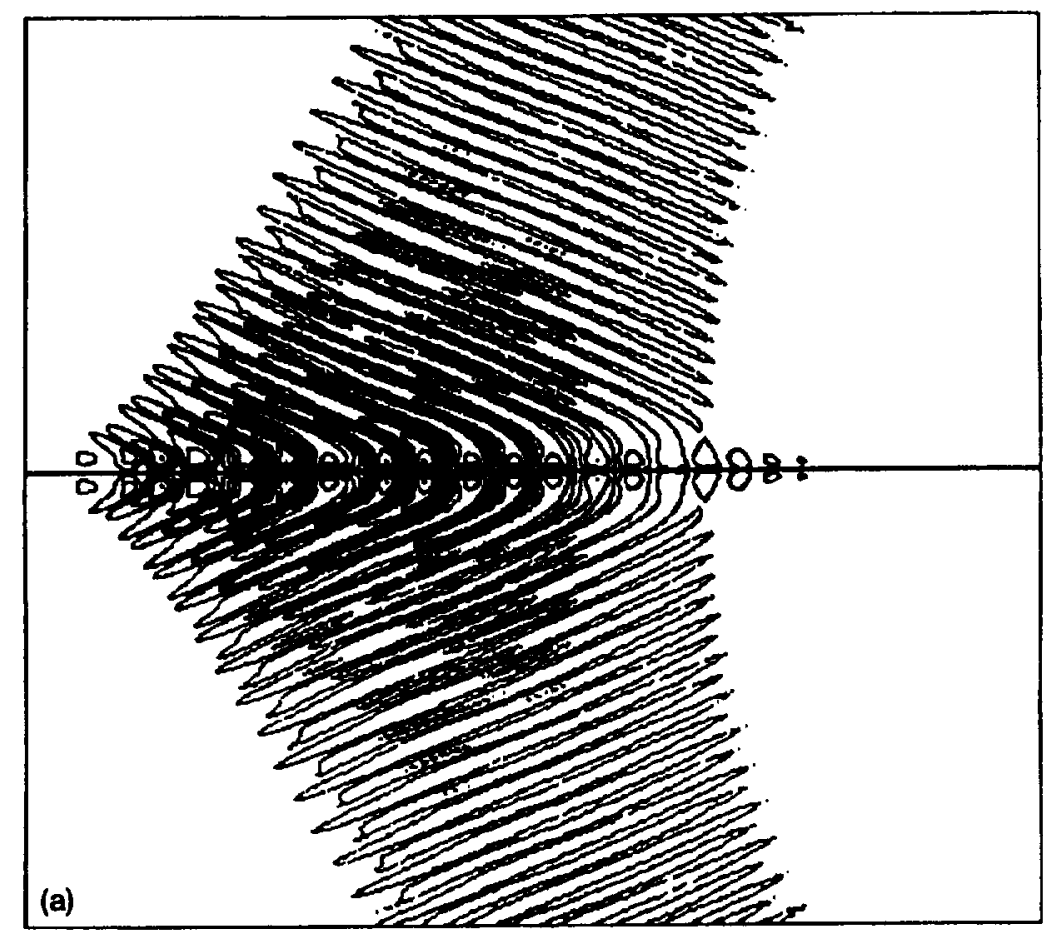

Figure 3. - Instantaneous pressure distributions. (a) In reference jet. (b) In normal velocity profile jet. (c) In inverted velocity profile jet. 

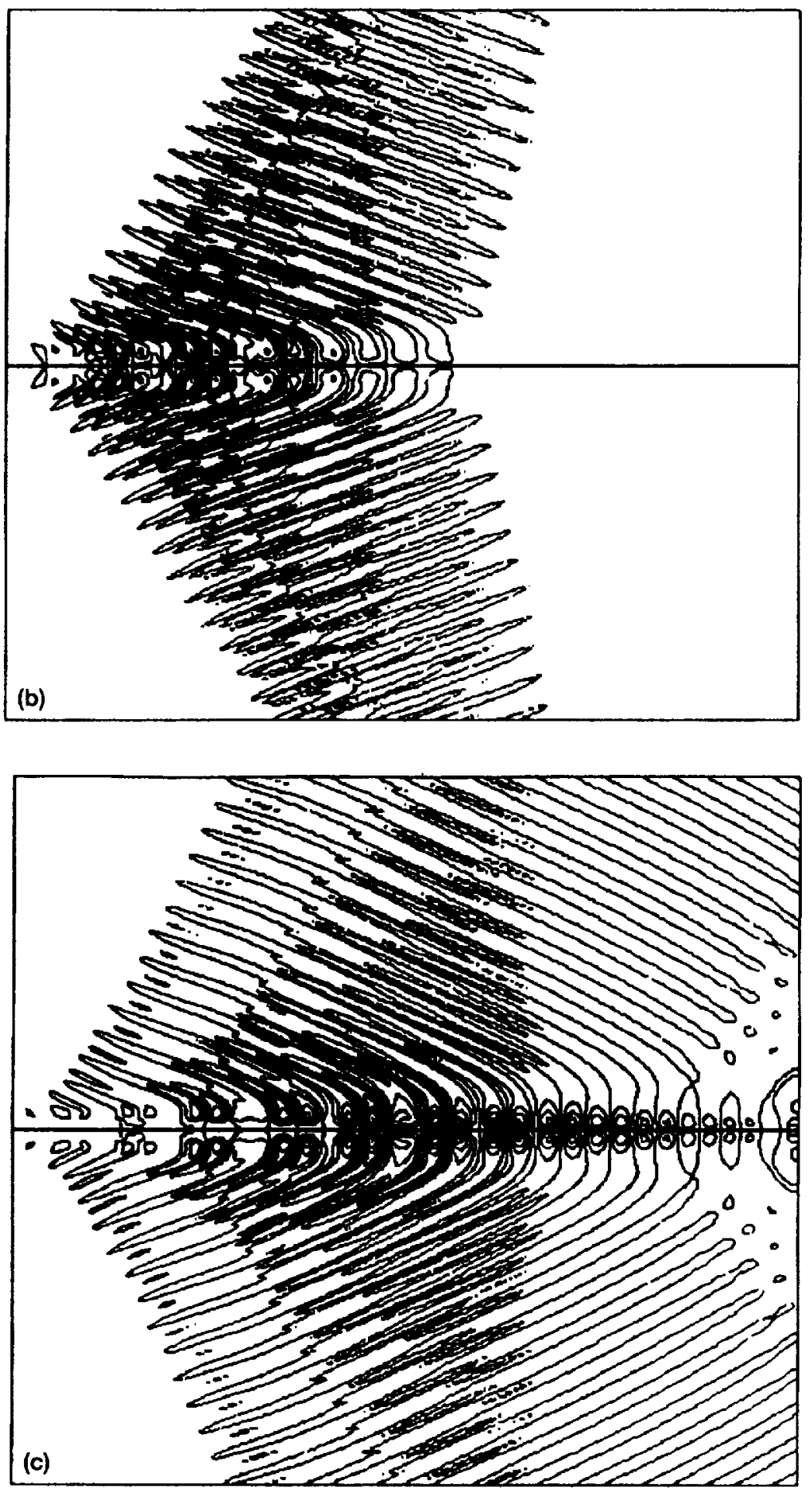

Figure 3.-Concluded. (b) In normal velocity profile jet. (c) In inverted velocity profile jet. 

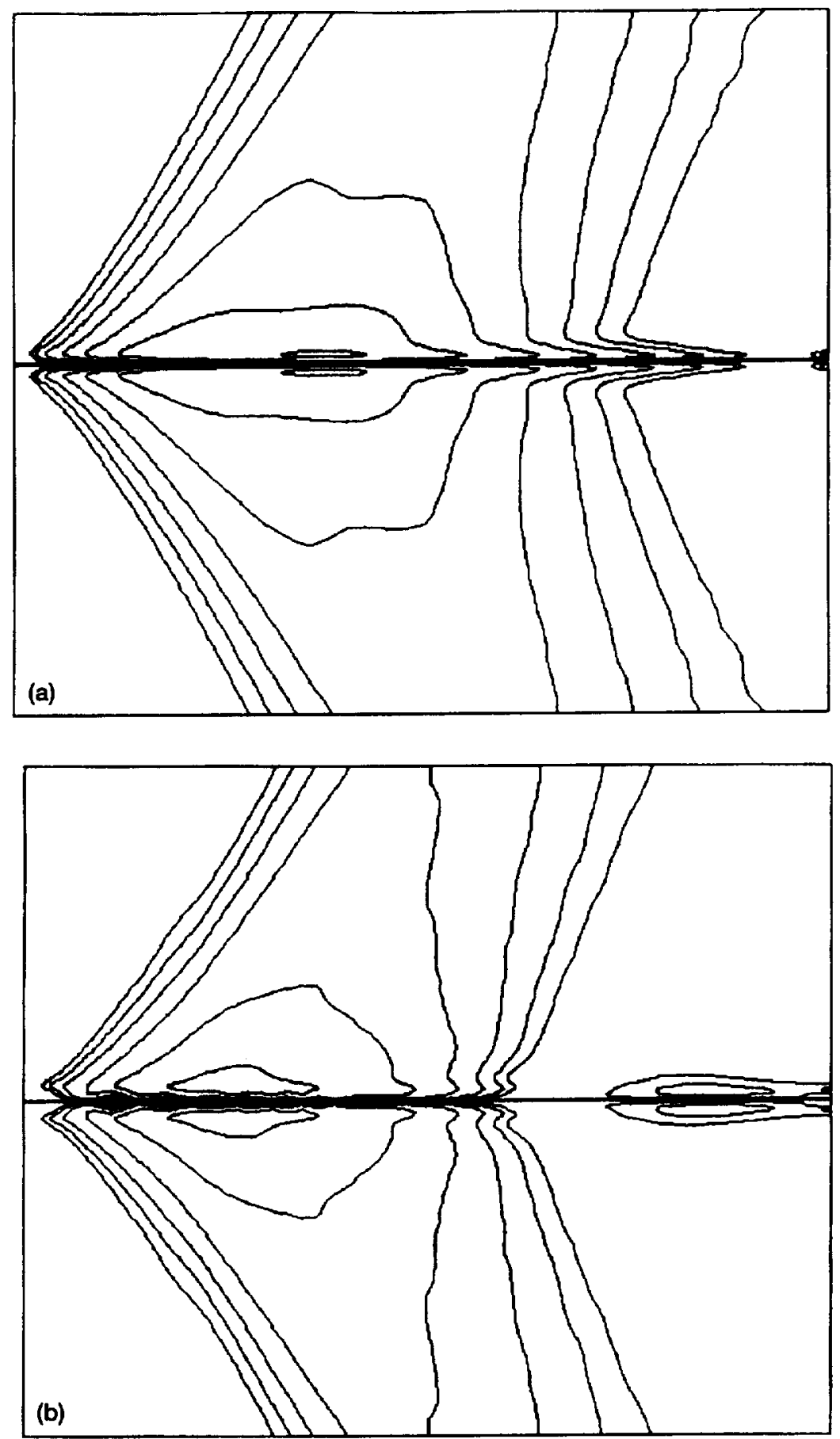

Figure 4.-Sound pressure level contours. (a) For reference jet. (b) For normal velocity profile jet. (c) For inverted velocity profile jet. 


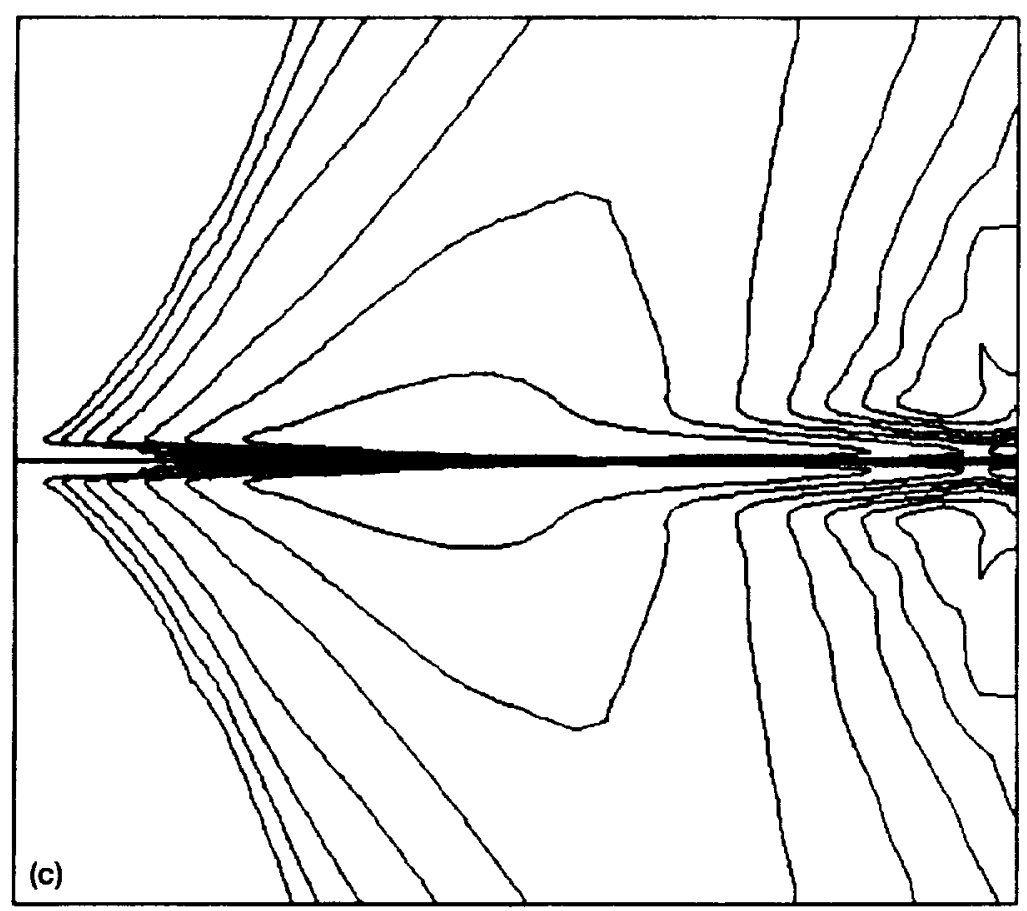

Figure 4.-Concluded. (c) For inverted velocity profile jet.

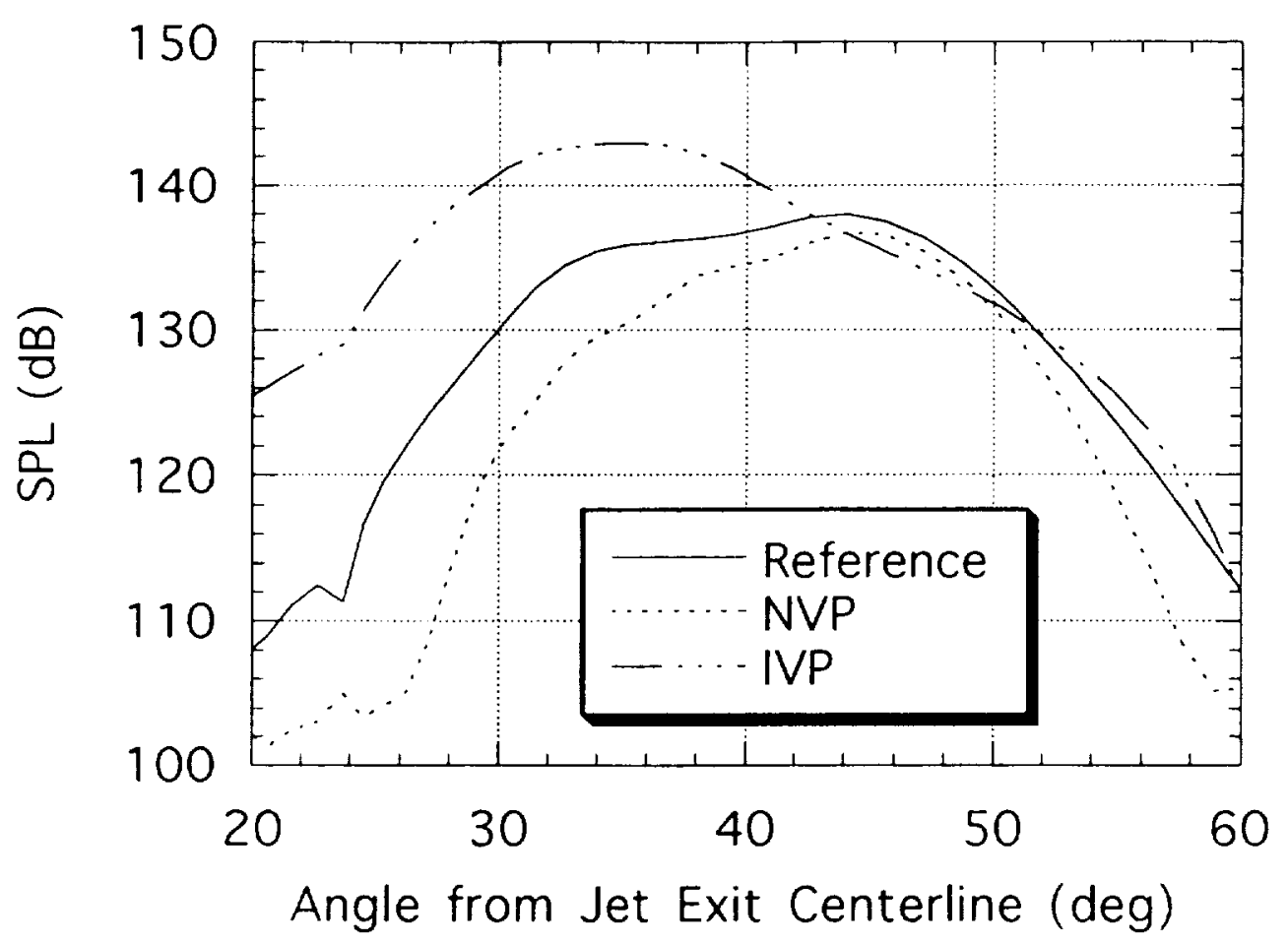

Figure 5.-Noise directivity results for coannular jet test cases. 
Public reporting burden for this collection of information is estimated to average 1 hour per response, including the time for reviewing instructions, searching existing data sources, gathering and maintaining the data needed, and completing and reviewing the collection of information. Send comments regarding this burden estimate or any other aspect of this collection of information, including suggestions for reducing this burden, to Washington Headquarters Services, Directorate for Information Operations and Repons, 1215 Jefle
1. AGENCY USE ONLY (Leave blank)
2. AEPORT DATE
May 1997
3. REPORT TYPE AND DATES COVERED
Contractor Report

4. TITLE AND SUBTITLE

Effect of Coannular Flow on Linearized Euler Equation Predictions of Jet Noise

6. AUTHOR(S)

R. Hixon, S.-H. Shih, and Reda R. Mankbadi

5. FUNDING NUMBERS

WU-523-36-13

NCC3-531

Institute for Computational Mechanics in Propulsion

22800 Cedar Point Road REPORT NUMBER

Cleveland, Ohio 44142

E-10718

9. SPONSORINGMONITORING AGENCY NAME(S) AND ADDRESS(ES)

10. SPONSORINGMONITORING

AGENCY REPORT NUMBER

National Aeronautics and Space Administration

Lewis Research Center

Cleveland, Ohio 44135-3191

NASA CR-202339

ICOMP-97-05

11. SUPPLEMENTARY NOTES

R. Hixon and S.-H. Shih, Institute for Computational Mechanics in Propulsion, NASA Lewis Research Center, (work funded under NASA Cooperative Agreement NCC3-531); Reda R. Mankbadi, Mechanical Power Engineering Department, Cairo University, Cairo, Egypt. ICOMP Program Director, Louis A. Povinelli, organization code 5800, (216) 433-5818.

12a. DISTRIBUTION/AVAILABILITY STATEMENT

12b. DISTAIBUTION CODE

Unclassified - Unlimited

Subject Category or Categories 64 and 71

This publication is available from the NASA Center for AeroSpace Information, (301) $621 \_0390$

13. ABSTRACT (Maximum 200 words)

An improved version of a previously validated linearized Euler equation solver is used to compute the noise generated by coannular supersonic jets. Results for a single supersonic jet are compared to the results from both a normal velocity profile and an inverted velocity profile supersonic jet.

14. SUBJECT TERMS

15. NUMBER OF PAGES

Supersonic jet noise; Computational aeroacoustics; MacCormack-type scheme; Dispersion relation preserving scheme

16. PRICE CODE

A03

\begin{tabular}{|c|c|c|}
\hline $\begin{array}{c}\text { 17. SECURTY CLASSIFICATION } \\
\text { OF REPORT } \\
\text { Unclassified }\end{array}$ & $\begin{array}{c}\text { 18. SECURTY CLASSIFICATION } \\
\text { OF THIS PAGE } \\
\text { Unclassified }\end{array}$ & $\begin{array}{c}\text { 19. SECURITY CLASSIFICATION } \\
\text { OF ABSTRACT } \\
\text { Unclassified }\end{array}$
\end{tabular}

